\title{
Bombardment history of Asteroid 4 Vesta recorded by brecciated eucrites: Large impact event clusters at 4.50 Ga and discreet bombardment until 3.47 Ga.
}

\author{
F. Jourdan ${ }^{1}$, T. Kennedy ${ }^{1}$ E. Eroglu ${ }^{1}$, C. Mayers ${ }^{1}$ \\ ${ }^{1}$ WAAIF; Department of Applied Geology and JdLC, Curtin University, Perth, Australia.
}

Eucrites are extraterrestrial basalts and cumulate gabbros formed, and subsequently more or less metamorphosed, at the crustal level of the HED (Howardite-Eucrite-Diogenite) parent body, thought to be the asteroid 4-Vesta. Studying brecciated eucrites using the ${ }^{40} \mathrm{Ar}{ }^{39} \mathrm{Ar}$ technique offers the best way to understand the bombardement history of 4-Vesta [1].

Early pioneer ${ }^{40} \mathrm{Ar} /{ }^{39} \mathrm{Ar}$ studies [1] suggested that brecciated eucrites have impact ages between $~ 4.1-3.4$ Ga. However, Kennedy et al. [2] presented an ( $>70 \% 39 \mathrm{Ar}$ plateau) age quality filtered database along with new robust ${ }^{40} \mathrm{Ar}{ }^{39} \mathrm{Ar}$ plateau ages on brecciated eucrites suggesting instead ages between $\sim 3.8$ and 3.5 Ma. Nevertheless, the total number of plateau ages was quite small, possibly creating a sample bias [2]. In this study, plagioclase, matrix and melt rock aliquots from fourteen brecciated eucrites were examined by the ${ }^{40} \mathrm{Ar}{ }^{\beta 9} \mathrm{Ar}$ techniques to provide a more robust statistical record for the impact heating history of 4-Vesta. We obtained two distinct population of ages.

We obtained a new concordant $(\mathrm{P}=0.16)$ concentration of six plagioclase and three matrix plateau ages from three polymict breccia with a weighted mean age of $4500 \pm 4 \mathrm{Ma}(2 \sigma)$. This is resolvably younger than the series of crustal cooling ${ }^{40} \mathrm{Ar} /{ }^{39} \mathrm{Ar}$ plateau ages ranging from $4533 \pm 12 \mathrm{Ma}$ to $4514 \pm 6 \mathrm{Ma}$ recorded by a series of (unshocked) unbrecciated eucrites [3], except for Agoult which yielded a cooling age of $4493 \pm 9 \mathrm{Ma}$ (Iizuka, this meeting). We interpret such an age concentration as indicating a single large-scale heating event recorded by several unrelated meteorites. The fact that such a cluster of ages is recorded in unrelated breccia which are made of a priori unrelated components, leads us to propose that those ages recorded a single heating event on a large scale, and is interpreted here as a mega impact event, early in the history of Vesta at $4500 \pm 4$ Ma. We propose that the debris were ejected and isolated from subsequent large impacts in a secondary rubble pile asteroid. Could this event be related to the Veneneia impact?

When combined with the results from [2], we obtain a total of eleven plateau ages ranging from $3851 \pm 21$ Ma to $3469 \pm 35$ Ma. An additional "lucky" plateau age of $4288 \pm 38 \mathrm{Ma}$ along with published U-Pb apatite age of $\sim 4.14 \mathrm{Ga}$ suggests that the data might either define a true continuum (normal background bombardment) from $4.5 \mathrm{Ga}$ to $3.47 \mathrm{Ga}$ or cluster between $\sim 3.85$ $\mathrm{Ga}$ and $\sim 3.47 \mathrm{Ga}$ (excavation of a fresh surface at $3.85 \mathrm{Ga}$ continuously bombarded until $3.47 \mathrm{Ga}$ ) until ejection from Vesta. Both scenarios are compatible with a final ejection age of $3.47 \mathrm{Ga}$ where a major impact liberates the bulk of the brecciated meteorites into another secondary rubble pile asteroid, where the brecciated eucrites stayed relatively well protected from subsequent major impacts. Based on these results and recent crater counting measurements, we propose that the excavation and bulk ejection were caused by the Rheasilvia (ca. $3.47 \mathrm{Ga}$ ) basin-forming impact.

\section{References}

Bogard D. D. (2011) K-Ar ages of meteorites: Clues to parent-body thermal histories. Chemie der Erde 71, 207-226.

Jourdan F., Kennedy T., Benedix G., Eroglu E. and Mayers, C. (2016) 40Ar/39Ar thermochronology of unbrecciated eucrites: clues to the crustal formation of Vesta. (This meeting).

Kennedy T., Jourdan F., Bevan A. W. R., Gee M. A. M., and Frew A. (2013) Impact history of the HED parent body(ies) clarified by new 40Ar/39Ar analyses of four HED meteorites and one anomalous achondrite. Geochim. Cosmochim. Acta 115, $162-182$.

Iizuka T., Jourdan F., Yamaguchi A., Koefoed P., Hibiya Y. and Amelin Y. Evidence for burial metamorphism on Vesta from $\mathrm{Pb}-\mathrm{Ar}$ chronology of the Agoult eucrite. (This meeting). 